Dossiê Especial: Experiências do PIBID na formação inicial e continuada de professores de

línguas estrangeiras

HIBARINO \& NODARI (orgs)

Revista X, vol.1, 2015

\title{
“O PIBID ME SALVOU": A TECNOLOGIZAÇÃO DE DISCURSOS E SUAS IMPLICAÇÕES NAS PRÁTICAS DE FORMAÇÃO DE PROFESSORES/AS
}

\begin{abstract}
"PIBID saved me": the technologisation of discourse and its implications on teacher education practices
\end{abstract}

\author{
Elaine Fernandes MATEUS ${ }^{1}$ \\ Vinícius OLIVEIRA ${ }^{2}$ \\ Camila Christiane Clivati SODRÉ ${ }^{3}$
}

\begin{abstract}
Resumo: Tecnologização de discursos diz respeito à "intervenção calculada para alterar práticas discursivas como parte da engenharia da mudança social" (FAIRCLOUGH, [1995] 2010, p. 3). É um conceito que se liga à hegemonia pelo consenso e, por esta razão, central neste estudo motivado pela necessidade da crítica às "parcerias universidade-escola" realizadas no interior do Programa Institucional de Bolsa de Iniciação à Docência (PIBID) que figura atualmente em cenário nacional brasileiro como espaço privilegiado para o desenvolvimento docente. Estudos recentes têm celebrado o Programa de modo a implicitamente promover a naturalização de ideologias que nele operam como mecanismos para manutenção de seu caráter hegemônico. Este trabalho tem o propósito de refletir sobre as implicações de tal hegemonia no contexto histórico de práticas de formação docente. Para tanto, analisamos narrativas de três licenciandas, bolsistas no Programa. Por meio de categorias de análise linguístico-discursivas, discutimos identidades das professoras, e o PIBID como entidade.
\end{abstract}

Palavras-chave: PIBID; hegemonia; tecnologização de discursos.

\begin{abstract}
Technologization of discourse is a "calculated intervention to shift discursive practices as part of the engineering of social change" (FAIRCLOUGH, [1995] 2010, p. 3). It involves the redesigning of discursive practices on the basis of hegemonic consensus. For this reason, it is a central concept in this article conceived out of a need to critique university-school partnerships enacted within an Institutional Bursary Program for the Initiation to Teaching (PIBID) that figures throughout Brazil as the privileged context for teacher development. Recent studies celebrate the Program implicitly promoting the naturalization of ideologies that function as mechanisms to maintain its hegemonic aspects. This research aims at reflecting about the implications of its hegemonic character on teacher education practices. We do so by analyzing narratives from three student teachers granted by PIBID. By the use of discursive-linguistic categories we analyze teachers' identities and the Program as an entity.
\end{abstract}

Keywords: PIBID, hegemony, technologization of discourse.

\footnotetext{
${ }^{1}$ Doutora. Universidade Estadual de Londrina. mateus@uel.br.

${ }^{2}$ Mestrando na Universidade Estadual de Londrina. vinistorm@uel.br.

${ }^{3}$ Pós-graduada em Língua e Literatura Inglesa e professora da SEED/PR. camila@camilaclivati.com.
} 


\section{Dossiê Especial: Experiências do PIBID na formação inicial e continuada de professores de línguas estrangeiras \\ HIBARINO \& NODARI (orgs) \\ Revista X, vol.1, 2015}

\section{Introdução}

Tem sido constante na área de formação docente o empenho em fomentar práticas que promovam professores/as competentes, autônomos/as e críticos/as, capazes de lidar com os desafios de uma sociedade cada vez mais complexa e hipersemiotizada (por exemplo, SCHÖN, 1988; SMYTH, 1992; ZEICHNER, 2003; HARGREAVES, FULLAN, 2012, para citar alguns trabalhos representativos destas correntes nas quatro últimas décadas). Na esteira destas questões caras a educadores/as, e com o propósito de atuar nas lacunas e demandas próprias das licenciaturas (SCHEIBE, 2010), a Coordenação de Aperfeiçoamento de Pessoal de Nível Superior (Capes), desde 2007, oferece incentivos a professores/as da educação básica, professores/as da educação superior e estudantes dos cursos de licenciatura no Brasil, para o desenvolvimento de projetos nas escolas públicas de educação básica, por meio do Programa Institucional de Bolsas de Iniciação à Docência (PIBID). Dentre os objetivos do Programa, está o de incentivar a formação de docentes para o ensino básico e proporcionar oportunidades (inovadoras) de formação a licenciandos/as, em conjunto com professores/as da educação superior e da educação básica, buscando promover diálogo entre universidade e escola. Em linhas gerais, o Programa consiste em conceder recursos às Instituições de Ensino Superior (IES) e bolsas ${ }^{4}$ aos/às envolvidos/as. Em algumas IES, os projetos aprovados pela Capes são abrigados nas Pró-Reitorias de Graduação e, além da bolsa para coordenação de área $^{5}$, os docentes das IES têm horas atribuídas em suas planilhas para cada estudante que integra seu subprojeto ${ }^{6}$.

Neste cenário, há uma profusão de estudos que analisam o PIBID sob diferentes perspectivas e com diferentes propósitos. Como veremos adiante, é comum a muitos a celebração do Programa e a naturalização de ideologias que nele operam como mecanismos para manutenção de seu caráter hegemônico. Isto porque, na medida em que o Programa se insere em um conjunto de práticas sociais desenhadas para direcionar e controlar o curso das

\footnotetext{
${ }^{4}$ As modalidades e valores mensais de bolsas, conforme Edital Capes 061/2013, são: coordenação institucional - docente da IES coordenador/a do projeto institucional - R \$ 1.500,00; coordenação de área de gestão de processos educacionais - docente da IES auxiliar na coordenação do projeto institucional - R\$1.500,00; coordenação de área - docente da IES coordenador/a do subprojeto da sua área - R\$1.400,00; supervisão docente da rede pública de educação básica que supervisiona licenciandos/as - $\mathrm{R} \$ 765,00$; iniciação à docência - estudantes da licenciatura - R\$ 400,00.

${ }^{5}$ Coordenadores/as de área são responsáveis por, no mínimo, 5 estudantes de licenciatura e 1 supervisor/a da educação básica e, no máximo, 20 estudantes de licenciatura e 2 supervisores/as (Edital Capes 061/2013, disponível em http://www.capes.gov.br/educacao-basica/capespibid/editais-e-selecoes, acesso em 15 de agosto de 2013).

${ }^{6}$ É o caso da Universidade Estadual de Londrina, cuja proposta de resolução que regulamenta tal prática encontra-se em discussão.
} 


\title{
Dossiê Especial: Experiências do PIBID na formação inicial e continuada de professores de línguas estrangeiras \\ HIBARINO \& NODARI (orgs) \\ Revista X, vol.1, 2015
}

mudanças que afetam a sociedade contemporânea (MATEUS, 2014), diminuem as possibilidades de contestação e resistência. A isto Fairclough ([1995] 2010, p. 137) chama de tecnologização do discurso e define como

\begin{abstract}
... um processo de intervenção na esfera das práticas de discurso com o objetivo de construir uma nova hegemonia na ordem do discurso da instituição ou organização envolvida, como parte de uma disputa mais abrangente para impor hegemonias reestruturadas na cultura e práticas institucionais [...] Isso é feito por meio de um processo de redesenhamento de práticas discursivas existentes e de treinamento das pessoas que atuam na instituição nestas práticas redesenhadas, com base em pesquisas no interior das práticas discursivas existentes na instituição e sua efetividade. ${ }^{7}$
\end{abstract}

Constitui parte deste fenômeno, a incorporação das IES como peça central na estrutura criada para o PIBID, uma vez que hegemonia, como argumenta Fairclough ([1995] 2010, p. 61), "diz respeito à construção de alianças e à integração, ao invés de simplesmente à dominação de classes subordinadas, por meio de concessões ou por meio de recursos

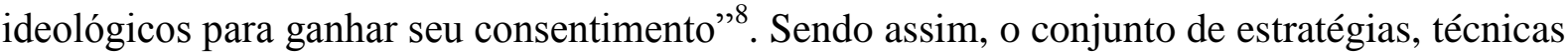
e procedimentos por meio dos quais hegemonias são operacionalizadas é complexo e envolve diferentes forças, normas, rotinas, discursos.

Tendo em vista tais questões, os dados que analisamos neste texto, assim como outros relatos de pesquisa aos quais recorremos, permitem refletir sobre o caráter hegemônico do PIBID, instanciado em práticas discursivas locais, mais especificamente em contextos particulares das instituições de ensino. Reconhecendo a natureza dialógica da linguagem, esperamos que este texto possa contribuir para resistência criativa e provocar reflexões que promovam uma possível saturação e o rompimento com práticas discursivas padronizadoras (CHOULIARAKI; FAIRCLOUGH, 1999).

O artigo está organizado da seguinte maneira. A primeira seção apresenta uma revisão de estudos sobre o PIBID, capturados nas bases de dados Scielo e Periódicos Capes. O propósito desta revisão é identificar os modos como o Programa tem sido representado em termos de seus impactos e limitações. A segunda seção apresenta os resultados da pesquisa que realizamos a fim de investigar o que dizem 3 licenciandas egressas sobre o Programa. Os

\footnotetext{
${ }^{7}$... a process of intervention in the sphere of discourse practices with the objective of constructing a new hegemony in the order of discourse of the institution or organization concerned, as port of a more general struggle to impose restructured hegemonies in institutional practices and culture [...] This is done through a process of redesigning existing discursive practices and training institutional personnel in the redesigned practices, on the basis of research into the existing discursive practices of the institution and their effectiveness.

${ }^{8}$... is about constructing alliances, and integrating rather than simply dominating subordinate classes, through concessions or through ideological means, to win their consent.
} 
Dossiê Especial: Experiências do PIBID na formação inicial e continuada de professores de

línguas estrangeiras

HIBARINO \& NODARI (orgs)

Revista X, vol.1, 2015

dados coletados por meio de narrativas corroboram resultados de outros estudos quanto à importância do PIBID sobre suas identidades de professoras e somam-se de forma unívoca a muito do que se tem dito sobre o referido programa nos últimos anos. Frente a estes resultados, problematizamos o caráter hegemônico do PIBID, representado neste estudo, e reiterado em outros, como entidade. Assim, a terceira e última seção discute algumas implicações de processos de padronização de práticas discursivas sobre práticas de formação de professores/as.

\section{Implicações do PIBID na formação docente}

Inserido num projeto de reforma universitária iniciada na década de 90, o PIBID se coloca na conjuntura das propostas promulgadas pelo Plano de Desenvolvimento da Educação (PDE), composto por um pacote de medidas na área e constituído por um conjunto de normativas, como os Decretos $\mathrm{n}^{0}$ 6.093, que dispõe sobre a reorganização do Programa Brasil Alfabetizado, ${ }^{0}$ 6.094, que dispõe sobre a implementação do Plano de Metas Compromisso Todos pela Educação ${ }^{9}, \mathrm{n}^{0}$ 6.095, que estabelece as diretrizes dos Institutos Federais de Educação e ${ }^{0}$ 6.096, que institui o Programa de Apoio a Planos de Reestruturação e Expansão das Universidades Federais - Reuni.

$\mathrm{Na}$ esteira de experiências vivenciadas em outros países, o conceito de parceria universidade-escola se apresenta no PIBID como estratégia de gerenciamento da crise presente nas licenciaturas. Como panacéias (KENNEDY; DOHERTY, 2012) - isto é, como soluções políticas promovidas explícita ou implicitamente como cura para todas as questões , os documentos oficiais que regulamentam o PIBID definem formas de gerenciamento e prescrições que se tornam tão estabelecidas a ponto de sua eficácia parecer evidente e, por esta razão, difícil de ser questionada. Isto porque, são documentos que incorporam críticas fomentadas nas ciências - a exemplo da dicotomia entre teoria e prática, entre universidade e escola - e operam por meio de estratégias e procedimentos que visam a articular forças

\footnotetext{
${ }^{9}$ O movimento "Compromisso Todos pela Educação" foi lançado em 6 de setembro de 2006, em São Paulo e, embora apresentado como uma iniciativa da sociedade civil, deu-se a partir de grupos empresariais com representantes e patrocínio de entidades como o Grupo Pão de Açúcar, Fundação Itaú-Social, Fundação Bradesco, Instituto Gerdau, Fundação Roberto Marinho, Instituto Ayrton Senna, Banco ABN-Real, Banco Santander, Instituto Ethos, entre outros (SAVIANI, 2007).
} 
Dossiê Especial: Experiências do PIBID na formação inicial e continuada de professores de

línguas estrangeiras

HIBARINO \& NODARI (orgs)

Revista X, vol.1, 2015

contraditórias em sentido único - por meio, por exemplo, do incentivo financeiro para operacionalização do Programa ${ }^{10}$.

Com tais aspectos em mente, esta seção busca identificar os modos como o PIBID tem sido representado em termos de seus impactos e limitações. Para tanto, recorremos às bases de dados Scielo e Periódicos Capes.

Em ambas as bases de dados, fora realizadas duas buscas. Na primeira, por parâmetro temático, o termo utilizado foi "PIBID", em todos os campos, em publicações do tipo periódicos. O parâmetro cronológico compreendeu o período de 2007-2014/1, sendo 2007 o ano em que o Programa foi proposto pelo governo federal e 2014/1 o ano e o semestre da realização deste estudo. Desta busca, resultaram 32 trabalhos conforme quadro a seguir:

\begin{tabular}{|l|l|}
\hline Base de dados & PIBID \\
\hline Scielo & 6 estudos \\
\hline Capes & 26 estudos \\
\hline
\end{tabular}

Quadro 1: Número de trabalhos que contêm a palavra PIBID em qualquer campo, disponíveis nas bases de dados Scielo e Capes

A segunda busca teve como critério de inclusão os artigos publicados em "periódicos revisados por pares". Após leitura exploratória dos resumos, que nos permitiu identificar os artigos que efetivamente se referiam ao PIBID - Programa da Capes, restaram os trabalhos seguintes, que são objeto desta revisão.

\begin{tabular}{|l|c|l|l|}
\hline \multicolumn{1}{|c|}{ Autor/a/es/as } & Ano & \multicolumn{1}{c|}{ Título } & \multicolumn{1}{c|}{ Fonte } \\
\hline ANDRÉ, Marli & 2012 & $\begin{array}{l}\text { Políticas e programas de apoio } \\
\text { aos professores iniciantes no } \\
\text { Brasil }\end{array}$ & $\begin{array}{l}\text { Cadernos de Pesquisa, v.42, } \\
\text { n.145, p.112-129. }\end{array}$ \\
\hline $\begin{array}{l}\text { FETZNER, Andréa } \\
\text { Rosana; SOUZA, } \\
\text { Maria Elena V. }\end{array}$ & 2012 & $\begin{array}{l}\text { Concepções de conhecimento } \\
\text { escolar: potencialidades do } \\
\text { Programa Institucional de Bolsa } \\
\text { de Iniciação à Docência }\end{array}$ & $\begin{array}{l}\text { Educação e Pesquisa, v.38, } \\
\text { n.3, p.683-694. }\end{array}$ \\
\hline $\begin{array}{l}\text { BERGAMASCHI, } \\
\text { Maria Aparecida; } \\
\text { ALMEIDA, Dóris } \\
\text { B. }\end{array}$ & 2013 & $\begin{array}{l}\text { Memoriais escolares e processos } \\
\text { de iniciação à docência }\end{array}$ & $\begin{array}{l}\text { Educação em Revista, v.29, } \\
\text { n.2, p.15-41. }\end{array}$ \\
\hline MATEUS, Elaine & 2013 & $\begin{array}{l}\text { Práticas de formação } \\
\text { colaborativa de professores/as de }\end{array}$ & $\begin{array}{l}\text { Revista Brasileira de } \\
\text { Linguística Aplicada, v.13, }\end{array}$ \\
\hline
\end{tabular}

\footnotetext{
${ }^{10}$ Para uma crítica sobre parcerias na formação de professores/as e sobre o PIBID como peça nesta engrenagem, ver Mateus (2014).
} 
Dossiê Especial: Experiências do PIBID na formação inicial e continuada de professores de línguas estrangeiras

HIBARINO \& NODARI (orgs)

Revista X, vol.1, 2015

\begin{tabular}{|l|l|l|l|}
\hline & & $\begin{array}{l}\text { inglês: representações de uma } \\
\text { experiência no PIBID }\end{array}$ & n.4, p.1107-1130. \\
\hline $\begin{array}{l}\text { NEITZEL, Adair A.; } \\
\text { PAREJA, Cleide J. } \\
\begin{array}{l}\text { M.; HOCHMANN, } \\
\text { Serenita. }\end{array}\end{array}$ & 2013 & $\begin{array}{l}\text { Práticas de leitura no ensino } \\
\text { médio: o PIBID de Letras. }\end{array}$ & $\begin{array}{l}\text { Revista Brasileira de } \\
\text { Estudos Pedagógicos, v.94, } \\
\text { n.238, p.770-794. }\end{array}$ \\
\hline $\begin{array}{l}\text { ALBUQUERQUE, } \\
\text { Mayra P.; FRISON, } \\
\begin{array}{l}\text { Lourdes Maria B.; } \\
\text { PORTO, Gilceane } \\
\text { C. }\end{array}\end{array}$ & 2014 & $\begin{array}{l}\text { Memorial de formação escrito no } \\
\text { decorrer da prática docente: } \\
\text { aprendizagens sobre } \\
\text { alfabetização e letramento }\end{array}$ & $\begin{array}{l}\text { Revista Brasileira de } \\
\text { Estudos Pedagógicos, v.95, } \\
\text { n.239, p.73-86. }\end{array}$ \\
\hline
\end{tabular}

Quadro 2: Trabalhos revisados neste artigo

Para este estudo, analisamos os seguintes aspectos nos trabalhos encontrados: objetivos e enfoques, conceitos-chave explorados ou pilares teóricos, metodologia de trabalho e principais resultados. O quadro 3 sintetiza estes dados. 
Dossiê Especial: Experiências do PIBID na formação inicial e continuada de professores de línguas estrangeiras HIBARINO \& NODARI (orgs)

Revista X, vol.1, 2015

\begin{tabular}{|c|c|c|c|c|}
\hline Autor/Ano & $\begin{array}{l}\text { Objetivos/ } \\
\text { Enfoques }\end{array}$ & $\begin{array}{l}\text { Conceitos-chave } \\
\text { Pilares teóricos }\end{array}$ & Metodologia de pesquisa & Principais resultados \\
\hline $\begin{array}{l}\text { ANDRÉ, } \\
(2012)\end{array}$ & $\begin{array}{l}\text { Descrever e analisar políticas } \\
\text { voltadas à formação de } \\
\text { professores iniciantes e } \\
\text { programas que favorecem a } \\
\text { inserção na docência; mapear as } \\
\text { políticas relativas à formação, } \\
\text { carreira e avaliação dos } \\
\text { docentes da EB e os subsídios } \\
\text { oferecidos ao seu trabalho. }\end{array}$ & $\begin{array}{ll}\text { - } & \text { Evasão do magistério } \\
\text { - } & \text { Políticas voltadas para o } \\
\text { professor iniciante } \\
\text { - } \\
\text { Inserção de novos docentes }\end{array}$ & $\begin{array}{l}\text { Estudos de campo conduzidos em } \\
\text { cinco estados e em dez municípios } \\
\text { por meio da análise de documentos } \\
\text { oficiais da União, estados e } \\
\text { municípios brasileiros, revisão de } \\
\text { estudos acadêmicos, depoimentos e } \\
\text { entrevistas junto aos responsáveis } \\
\text { pelos órgãos gestores das políticas e } \\
\text { registros de campo. }\end{array}$ & $\begin{array}{l}\text { Aponta para a necessidade de delineamento de políticas de } \\
\text { apoio a docentes iniciantes e de formação de professores } \\
\text { mentores. O PIBID é abordado descritivamente em uma } \\
\text { seção intitulada "programas de inserção à docência: parcerias } \\
\text { entre universidade e escola". A autora indica não ter sido } \\
\text { feita ainda uma avaliação abrangente dos efeitos do Programa } \\
\text { na formação de professores e conclui que, apesar disto, "as } \\
\text { avaliaços pontuais que vêm sendo desenvolvidas (...) têm } \\
\text { evidenciado resultados muito positivos, seja na motivação } \\
\text { dos estudantes envolvidos, para ingressar na profissão, seja } \\
\text { nas disposições dos professores das escolas, que se sentem } \\
\text { desafiados a rever suas práticas em colaboração com os } \\
\text { novos atores do ambiente escolar" (p. 126). }\end{array}$ \\
\hline $\begin{array}{l}\text { FETZNER, Andréa } \\
\text { Rosana; SOUZA, } \\
\text { Maria Elena V. } \\
(2012)\end{array}$ & $\begin{array}{l}\text { Discutir concepções } \\
\text { conhecimento escolar que } \\
\text { permeiam os saberes da } \\
\text { docência de professores de } \\
\text { escolas públicas e de bolsistas } \\
\text { de ID envolvidos no PIBID; } \\
\text { discutir os desafios de um } \\
\text { projeto de transformação da } \\
\text { escola básica em uma } \\
\text { instituição que assuma } \\
\text { perspectivas interculturais em } \\
\text { relação ao conhecimento } \\
\text { escolar. }\end{array}$ & $\begin{array}{ll}\text { - } & \text { PIBID como espaço de } \\
& \text { conhecimento e formação } \\
\text { - } & \text { Interculturalidade } \\
\text { - } & \text { Conhecimento, saberes } \\
& \text { acadêmicos, fazer docente }\end{array}$ & 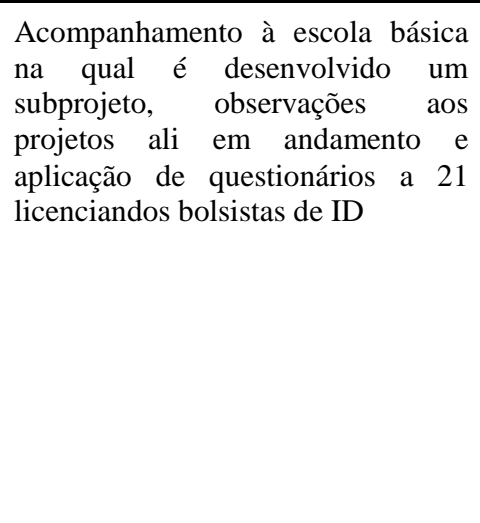 & $\begin{array}{l}\text { Os dados apontam que "a concepção de conhecimento } \\
\text { escolar tem oscilado entre perspectivas conservadoras e } \\
\text { perspectivas emancipatórias (...)" (p. 683). O PIBID é } \\
\text { caracterizado "como projeto de pesquisa" (p. 688) que } \\
\text { integra os componentes práticos, vivenciados nas escolas de } \\
\text { EB, aos teóricos, oriundos das pesquisas realizadas nas } \\
\text { universidades. Os resultados que tratam do que representa o } \\
\text { PIBID para a formação dos licenciandos assinalam o } \\
\text { Programa "como espaço de formação para a profissão de } \\
\text { professor e como espaço de ampliação das aprendizagens } \\
\text { dessa profissão" (p. 692). Concluem que "o referido } \\
\text { programa (...) tem contribuído para intensificar as } \\
\text { perspectivas interculturais no trato do conhecimento escolar, } \\
\text { (...)" (p. 693). }\end{array}$ \\
\hline $\begin{array}{l}\text { BERGAMASCHI, } \\
\text { Maria Aparecida; } \\
\text { ALMEIDA, Dóris } \\
\text { B. (2013) }\end{array}$ & $\begin{array}{l}\text { Analisar narrativas de } \\
\text { memoriais escritos ao longo do } \\
\text { ano de } 2011 \text { com o propósito de } \\
\text { produzir o livro Iniciação à } \\
\text { docência em Pedagogia: } \\
\text { memórias que contam histórias. }\end{array}$ & $\begin{array}{ll}\text { - } & \text { Memórias } \\
\text { - } & \text { Docência compartilhada } \\
\text { - } & \text { Parceria }\end{array}$ & $\begin{array}{l}\text { Análise de narrativas de memórias } \\
\text { de } 14 \text { alunos de Pedagogia, } \\
\text { bolsistas de ID, agrupadas nas } \\
\text { categorias "lembranças de } \\
\text { infância", "vivências familiares", } \\
\text { "experiências escolares", "escolha } \\
\text { pela docência", e "atuação e } \\
\text { aprendizagens no PIBID". }\end{array}$ & $\begin{array}{l}\text { A análise dos memoriais tornou possível uma releitura da } \\
\text { atuação e projeção profissional dos alunos bolsistas de ID. } \\
\text { Evidencia ainda o papel crucial que o PIBID desempenha no } \\
\text { processo de formação inicial e continuada, articulando os } \\
\text { saberes da escola e da universidade. Definido como "um } \\
\text { projeto bonito" (p. 16), o PIBID é representado como aquilo } \\
\text { que colabora no desenvolvimento de professores e que } \\
\text { promove a constituição de uma identidade de professor. }\end{array}$ \\
\hline $\begin{array}{c}\text { Autor/ } \\
\text { Ano }\end{array}$ & $\begin{array}{c}\text { Objetivos/ } \\
\text { Enfoques }\end{array}$ & $\begin{array}{l}\text { Conceitos-chave } \\
\text { Pilares teóricos }\end{array}$ & Metodologia de pesquisa & Principais resultados \\
\hline
\end{tabular}




\section{Dossiê Especial: Experiências do PIBID na formação inicial e continuada de professores de línguas estrangeiras}

HIBARINO \& NODARI (orgs)

Revista X, vol.1, 2015

\begin{tabular}{|c|c|c|c|c|}
\hline $\begin{array}{l}\text { MATEUS, Elaine } \\
(2013)\end{array}$ & 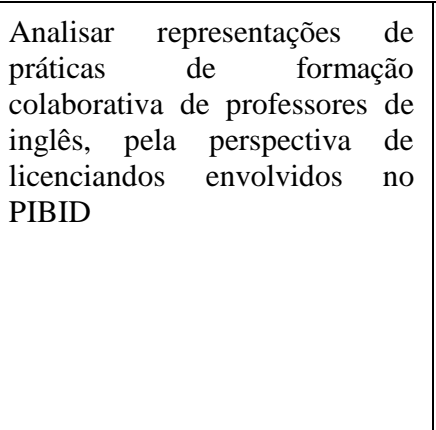 & $\begin{array}{ll}\text { - } & \text { Colaboração } \\
\text { - } & \text { Parceria universidade- } \\
\text { escola } \\
\text { - } & \text { Posicionamentos híbridos }\end{array}$ & $\begin{array}{l}\text { Aplicação de questionário em } \\
\text { escala Likert e realização de um } \\
\text { grupo focal com licenciandos } \\
\text { bolsistas de ID; dados estes } \\
\text { analisados com base na análise de } \\
\text { discurso crítica, por meio das } \\
\text { categorias de metáfora e de } \\
\text { avaliação. }\end{array}$ & $\begin{array}{l}\text { O estudo aponta para implicações que as posições híbridas } \\
\text { trazem para as práticas de formação de professores no } \\
\text { interior do PIBID. A análise indica tensões entre aquilo que } \\
\text { os documentos oficiais sobre o PIBID estabelecem como } \\
\text { lugar social dos licenciandos - reposicionados como "novos } \\
\text { profissionais", "inseridos no cotidiano de escolas" - e os } \\
\text { posicionamentos que ocupam na prática, condicionados por } \\
\text { relações hierarquicamente consolidadas. O texto critica o fato } \\
\text { de que subprojetos do PIBID sejam acomodados na } \\
\text { organização curricular vigente das IES, como somatória de } \\
\text { práticas e não como novos padrões de gerenciamento coletivo } \\
\text { de formação docente. }\end{array}$ \\
\hline $\begin{array}{l}\text { NEITZEL, Adair } \\
\text { A.; PAREJA, } \\
\text { Cleide J. M.; } \\
\text { HOCHMANN, } \\
\text { Serenita (2013) }\end{array}$ & $\begin{array}{l}\text { Analisar que estratégias de } \\
\text { leitura foram desenvolvidas por } \\
\text { licenciandos de Letras, durante } \\
\text { sua atuação no PIBID, que } \\
\text { concepções sustentam as } \\
\text { estratégias e como elas } \\
\text { colaboram para formação de } \\
\text { leitores no ensino médio. }\end{array}$ & $\begin{array}{ll}\text { - } & \text { Formação de leitores } \\
\text { - } & \text { Estratégias de leitura } \\
\text { - } & \text { Leitura fruitiva }\end{array}$ & $\begin{array}{l}\text { Análise de portfólios produzidos } \\
\text { pelos licenciandos durante o } \\
\text { desenvolvimento do projeto, } \\
\text { postados em ambiente virtual. }\end{array}$ & $\begin{array}{l}\text { Os resultados apontam para uma reflexão sobre a importância } \\
\text { da formação inicial do professor assim como para a } \\
\text { necessidade de se voltar a discutir a inovação na escola por } \\
\text { meio de estratégias de ensino que permitam formas } \\
\text { dialógicas de interação. O PIBID é apresentado como } \\
\text { contexto no interior do qual estratégias de leitura e de } \\
\text { formação de leitores foram desenvolvidas. Ele figura no } \\
\text { estudo, portanto, como um conjunto de ações nos campos do } \\
\text { que se chama "estudo e planejamento", "vivências } \\
\text { pedagógicas" e "avaliação". }\end{array}$ \\
\hline $\begin{array}{l}\text { ALBUQUERQUE, } \\
\text { Mayra P.; } \\
\text { FRISON, Lourdes } \\
\text { Maria B.; PORTO, } \\
\text { Gilceane C. (2014) }\end{array}$ & $\begin{array}{l}\text { Investigar as aprendizagens } \\
\text { realizadas por uma acadêmica } \\
\text { do curso de licenciatura em } \\
\text { Pedagogia, descritas em um } \\
\text { memorial reflexivo a partir de } \\
\text { vivências promovidas pelo } \\
\text { PIBID }\end{array}$ & $\begin{array}{ll}\text { - } & \text { Articulação teoria-prática } \\
\text { - } & \text { Práxis } \\
\text { - } & \text { Alfabetização e Letramento }\end{array}$ & $\begin{array}{l}\text { Análise de conteúdo de memorial } \\
\text { de formação, escrito por uma } \\
\text { bolsista de ID. }\end{array}$ & $\begin{array}{l}\text { Os resultados conferem ao PIBID um caráter inovador que } \\
\text { favorece uma aprendizagem significativa tanto para os } \\
\text { professores em formação quanto ao grupo com o qual esse } \\
\text { professor desenvolve o seu trabalho. Como afirmam as } \\
\text { autoras, "o PIBID é um programa inovador no âmbito da } \\
\text { educação, pois, por meio dele, os alunos das licenciaturas têm } \\
\text { a oportunidade de estar inseridos nas escolas, em contato com } \\
\text { a realidade escolar desde o início da graduação, qualificando, } \\
\text { desse modo, sua formação inicial e ainda contribuindo para } \\
\text { uma melhor qualidade de ensino nas escolas públicas ao } \\
\text { desenvolver metodologias inovadoras" (p. 83). }\end{array}$ \\
\hline
\end{tabular}

Quadro 3: Síntese dos estudos sobre PIBID nas bases de dados Scielo e Periódicos Capes no período de 2007-2014/1 


\section{Dossiê Especial: Experiências do PIBID na formação inicial e continuada de professores de línguas estrangeiras \\ HIBARINO \& NODARI (orgs) \\ Revista X, vol.1, 2015}

A análise destes relatos de base primária permite considerar a predominância de enfoques do PIBID como política necessária (ANDRÉ, 2012), capaz de fomentar a integração de componentes práticos e teóricos (FETZNER; SOUZA, 2012; BERGAMASCHI; ALMEIDA, 2013), com caráter inovador (NEITZEL; PAREJA; HOCHMANN, 2013; ALBUQUERQUE; FRISON; PORTO, 2014). Em alguns estudos, discutido como iniciativa de pesquisa (FETZNER; SOUZA, 2012), ou de ação (NEITZEL; PAREJA; HOCHMANN, 2013), o PIBID é representado como uma prática paralela embora, ao mesmo tempo, acomodada ao currículo dos cursos de licenciatura (MATEUS, 2013). Nestes casos, o Programa é colocado com certa autonomia em relação àquilo que é parte integrante da formação de professores/as, ou seja, como possível de existir fora do contexto próprio dos cursos de licenciatura.

As pressões por mudanças sociais que emanam da tecnologização de discursos são absorvidas e instanciadas de diferentes modos. Fairclough ([1995] 2010, p. 141), afirma que as pessoas "podem se submeter, podem tacitamente parecer submeterem-se, podem se recusar a ceder ou podem chegar a diferentes formas de acomodação e de acordos entre práticas existentes e novas técnicas" ${ }^{11}$. É o mesmo autor quem considera as acomodações e os compromissos entre aquilo que existe e o novo como as estratégias mais comuns, que se manifestam na ambivalência dos textos.

$\mathrm{Na}$ verdade, as iniciativas recentes no campo das políticas de formação de professores/as têm operado a favor da marketização ${ }^{12}$ das práticas discursivas das universidades (FAIRCLOUGH, 1993). As tensões entre práticas que instanciam relações entre universidade e escola, orientadas para pesquisa, em que a universidade figura como protagonista, e aquelas que instanciam relações orientadas para parceria, em que a escola ocupa esta posição, são acomodadas nos textos de relatos de pesquisa; ora reproduzindo o discurso oficial da Capes que define o PIBID como iniciativa voltada à qualidade e valorização do magistério e do professor da educação básica, mas definindo o Programa explicitamente como espaço de pesquisa (FETZNER; SOUZA, 2012), ora reproduzindo o discurso oficial da Capes, mas reiterando a universidade como o lugar da produção do conhecimento a ser consumido pela escola (NEITZEL; PAREJA; HOCHMANN, 2013;

\footnotetext{
11 ...may comply, they may tactically appear to comply, they may refuse to be budged, or they may arrive at all sorts of accommodations and compromises between existing practices and new techniques.

${ }^{12}$ Fairclough ([1995] 2010, p. 101) argumenta: "Institutions of higher education come increasingly to operate (under government pressure) as if they were ordinary business competing to sell their products to consumers".
} 


\section{Dossiê Especial: Experiências do PIBID na formação inicial e continuada de professores de línguas estrangeiras \\ HIBARINO \& NODARI (orgs) \\ Revista X, vol.1, 2015}

ALBUQUERQUE; FRISON; PORTO, 2014). Em todos estes casos, são relatos de pesquisa que manifestam uma tentativa de equilíbrio entre o papel consolidado do/a professor/a da educação superior como pesquisador/a e formador/a de outros docentes e aquele novo que o coloca no lugar de coordenador/a de uma formação que prescinde deles - como é proposto nos documentos da Capes (MATEUS, 2014) .

Com foco sobre a formação inicial, sobre a parceria universidade-escola e sobre a prática em detrimento da pesquisa, esta recontextualização do PIBID na voz dos documentos da Capes, conceituando-o e a seus impactos como se livres de contextos e descolados de práticas específicas, opera para a padronização de tais prática discursivas no interior e entre as instituições envolvidas.

\section{Um (novo?) Estudo sobre o PIBID}

O propósito inicial deste texto reside na análise de dados coletados ao longo de 2013 por Oliveira, coautor, e constitui um recorte de seu projeto de mestrado. Como bolsista do PIBID entre 2011-2012, seu interesse pelo Programa, o qual passou a ver como objeto de estudo, reside sobre a análise de possibilidades de trabalho democrático em contexto de turmas de ensino médio profissionalizante ${ }^{13}$. Assim, ao longo de 2013, como professorpesquisador, Oliveira participou de atividades na escola e na universidade, juntamente com a professora supervisora, Sodré, também coautora deste trabalho, e um grupo de 5 licenciandas bolsistas de ID. O projeto nesta escola encerrou-se no final de 2013 e, a fim de investigar as representações do PIBID por três destas estudantes, foi pedido que escrevessem uma narrativa de suas experiências e desenvolvimento como professoras no PIBID. O texto seguinte foi enviado a elas, por Sodré, via facebook:

\footnotetext{
${ }^{13}$ Por uma perspectiva democrática de educação, entendemos aquela em que a promoção das relações entre sujeitos da escola ocorre de forma deliberativa e fluida. Isso porque a sala de aula como um ambiente social reproduz ou recria relações de poder, as quais podem acontecer de forma democrática ou tirânica. No exercício democrático de educação, estudantes são encorajados/as a participar das decisões e a tornarem-se responsáveis por elas; são convidados/as a deliberar de forma não combativa e tomando as perspectivas dos outros; e, principalmente, são motivados/as a exercitar requisitos da vida social que só podem ser aprendidos no processo - como respeito, responsabilidade coletiva, diálogo, cidadania -, mas não de forma moralizante, e sim sempre de forma reflexiva e aberta a reformulações. Em uma perspectiva tirânica, individualista e competitiva, os/as alunos/as tendem a desconhecer sua atuação no mundo como agente de mudança e assim, desconhecer também sua responsabilidade sobre sua existência histórica.
} 


\section{Dossiê Especial: Experiências do PIBID na formação inicial e continuada de professores de línguas estrangeiras \\ HIBARINO \& NODARI (orgs) \\ Revista X, vol.1, 2015}

Dears!!! Gostaria, de coração, que vcs tirassem um tempinho e escrevessem para mim as impressões que vcs tiveram sobre a sala de aula, o PIBID e o que mais quiserem falar. Gostaria muito de "ouvi-los" por escrito, acredito que acrescentará muito para nossas vidas profissionais. Pensem no seguinte: "Redija um texto contando sobre a sua experiência e desenvolvimento enquanto professor no projeto PIBID."

Ao escrever o texto, considere os seguintes tópicos:

1) Quanto tempo está no projeto (ex: estou desde o segundo ano);

2) O que aprendeu ou não em relação aos seus conhecimentos de língua inglesa;

3) O que aprendeu ou não em relação às suas atitudes/didática como professor.

Só algumas linhas, não se preocupem com erros e outras coisas, não precisa nem colocar o nome. Podem me mandar no meu email fictício@ficticio.com. Estou no aguardo!!! Bjs!!!!

Responderam: Patrícia ${ }^{14}$ que ingressou no Programa logo após ter iniciado a graduação em 2011 sendo bolsista de ID há dois anos; Cristina, licencianda matriculada no quarto ano do curso e que participava do PIBID desde seu terceiro ano de graduação, momento em que se inicia o estágio em sala de aula, e que ficou no grupo por três anos (a bolsista ficou retida em uma disciplina no quarto ano, por isso continuou no projeto); e Priscila que, à época da coleta de dados, era bolsista no PIBID há dois anos, tendo participado de observação de aulas no primeiro e atuado como regente no segundo.

Os dados somam quatro páginas de texto em fonte Times New Roman, tamanho 12. Depois de coletados, os textos foram integralmente lidos e organizados em categorias temáticas, com base em critérios de recorrência nas narrativas. Uma vez agrupadas, as categorias temáticas foram analisadas com base em categorias de análise linguísticodiscursivas e assim nomeadas: 1) o PIBID e as identidades de professoras; 2) o PIBID como entidade.

\section{O PIBID e as identidades de professoras}

Parte da literatura recente sobre formação de professores/as tem se concentrado em discutir aspectos ligados à identidade e à identificação de licenciandos/as com a profissão (PICONI; MATEUS, 2011). Há estudos que tratam, de modo específico, das relações entre o PIBID e as identidades de professores/as (ANDRÉ, 2012; BERGAMASCHI; ALMEIDA, 2013).

\footnotetext{
${ }^{14}$ Todos os nomes das participantes são fictícios. Oliveira e Sodré, como coautores, mantêm suas identidades reveladas.
} 


\section{Dossiê Especial: Experiências do PIBID na formação inicial e continuada de professores de línguas estrangeiras \\ HIBARINO \& NODARI (orgs) \\ Revista X, vol.1, 2015}

Além destes, em trabalho realizado ao longo de 2012, Mateus e Resende (2014) analisam sete subprojetos na área de Letras-Inglês, de cinco IES, contemplados por Editais do PIBID entre 2009 e 2012 com o objetivo de explorar princípios de recontextualização ligados a atores sociais, seus papéis e (dis)posicionamentos nestas práticas específicas de formação de professores/as. Por meio da análise das representações de atores sociais (VAN LEEUWEN, 2008), as autoras definem o que chamam de posições flutuantes ${ }^{15}$ para discutir papéis sociais e relações de poder. Para elas, a hiper-classificação de posicionamentos híbridos ou intermediários para os/as licenciandos/as, recontextualizados nos subprojetos como 'alunoprofessor', 'futuro professor', 'professor licenciando', 'professor em formação inicial', 'professor aprendiz', indica

por um lado, as tensões próprias de quem transita entre dois mundos - o da universidade, como aluno/a, e o da escola, como "quase-professor/a", por outro, indica ser a posição em que os papéis estão menos consolidados e, portanto, aquela em que as dinâmicas das relações de poder têm maior peso. A inconstância desses (dis)posicionamentos flutuantes opera para processos de (des)identificações com a prática. Isso pode justificar a necessidade de que alguns/mas desses/as alunos/as se autodenominem 'Pibidianos' ou 'Pibideiros'. (MATEUS; RESENDE, 2014, p. 89).

É neste sentido que Santos e colaboradoras (2010) discutem o termo Pibideiros como um neologismo que marca descentralização de poder e apagamento das hierarquias:

A palavra Pibideiro carrega consigo a identidade da comunidade PIBID, identificando e aproximando sujeitos que a ela pertencem, criando, contudo, um grande poder de interação social no grupo. A partir dela os integrantes do grupo hierarquicamente bolsistas, supervisor, orientador e coordenador se encontram dentro da rede PIBID, tornando o nível de poder descentralizado. O termo Pibideiro é responsável pela transformação das estruturas hierárquicas existentes (SANTOS et al., 2010, p. 232).

Na direção que apontam Santos e colaboradoras (2010), os dados que analisamos revelam participantes em processo de identificação como professoras, ao mesmo tempo que em movimento de distanciamento do papel de estagiárias, como se lê em suas narrativas:

\footnotetext{
15 "Por posições flutuantes entendemos aquelas densamente recontextualizadas por diversas classificações, que posicionam atores sociais de modo inconstante, ora com significados próximos àqueles consolidados, ora com significados distintos. Nossa análise indica que posições flutuantes operam, nesse caso, para a indeterminação dos papéis sociais e indicam dinâmicas de poder não consolidadas. Assim, quanto maior a flutuação, ou seja, quanto maior a diversidade na representação por substituição, menor a consolidação do poder daquele grupo na prática recontextualizada". (MATEUS; RESENDE, 2014, p. 88).
} 


\section{Dossiê Especial: Experiências do PIBID na formação inicial e continuada de professores de línguas estrangeiras \\ HIBARINO \& NODARI (orgs) \\ Revista X, vol.1, 2015}

Excerto 1:

Cristina: linhas 23-26

Durante 2 anos dei aula com a Camila e praticamente todo fim de semana nos reunimos para prepararmos material para os alunos e acho que isso foi muito positivo para nosso desenvolvimento como professores.

Patricia: linhas 17-20

Você percebe que aquela turma de alunos é realmente sua, que você tem a responsabilidade pelo aprendizado deles e que se o trabalho for feito com seriedade, eles realmente te vêem como professora, não como estagiária ou coisa assim.

Priscila: linhas 4-5 [...] 9-11 [...] 16-20

No ano em que fui observar as aulas, comecei a imaginar como seria a oportunidade de estar ali na frente como professora [...] Em alguns momentos das aulas, imaginei como eu agiria naquelas situações, como eu ensinaria aquele conteúdo e fui me preenchendo da esperança de que eu poderia sim ser professora. [...] [A regência] Foi uma experiência enriquecedora, pois percebi que a cada aula que dava e a cada material que preparávamos para passar aos alunos, meu interesse aumentava e a minha identidade que no começo do ano era de aluna da UEL e bolsista do PIBID, passou a ser também de professora de Inglês no [nome da escola].

O texto de Cristina busca marcar sua posição de professora ao se colocar em igualdade com as ações próprias a professores/as regentes em seu cotidiano, como "[dar] aula com a Camila" e, com ela, "[preparar] material para os alunos". O uso do pronome na primeira pessoa do plural e do substantivo masculino pluralizado em "nosso desenvolvimento como professores", indica generalização do caráter valorativo de que "isso foi muito positivo". Nota-se que seu texto não a diferencia do lugar da professora supervisora, Camila, nem quanto às ações e tampouco quanto ao modo como representa positivamente estas ações sobre seu desenvolvimento.

Patricia, por sua vez, representa-se como de posse da turma, afirmando que "aquela turma de alunos é realmente sua". Pelo uso da modalização epistêmica asseverativa "realmente", Patrícia expressa uma avaliação sobre o valor e as condições de verdade do que diz, colocando-se como protagonista que tem em suas mãos, sem margem de dúvida, a turma e "a responsabilidade pelo aprendizado deles". Na medida em que o faz, ela não somente se representa no papel de professora, mas considera que, ao mesmo tempo, é vista pelos/as alunos/as neste papel ("eles realmente te veem como professora, não como estagiária ou coisa assim”). É relevante observar que sua identificação como professora se faz em oposição ao 


\section{Dossiê Especial: Experiências do PIBID na formação inicial e continuada de professores de línguas estrangeiras \\ HIBARINO \& NODARI (orgs) \\ Revista X, vol.1, 2015}

seu papel legítimo de estagiária, marcando seu distanciamento do lugar social que, de fato, desempenha como estudante de licenciatura.

Já Priscila representa a experiência em termos de imaginar-se professora para tornar-se professora; ou seja, de uma identidade de "aluna da UEL e bolsista do PIBID" para uma identidade "também de professora de inglês" na escola. Há dois aspectos importantes a serem considerados aqui. Primeiro, Priscila não nega sua identidade de aluna e de bolsista, mas agrega a estas a de professora. Ao contrário de Patricia, reconhece-se na função social de licencianda em processo de iniciação à docência. Segundo, ela atribui à regência esta transformação identitária e não ao PIBID. Isto significa que a possibilidade de estar em sala de aula figura como agente desencadeador de seu processo identitário de professora.

Por um lado, estas são narrativas que corroboram os movimentos de identificação de licenciandos/as com a profissão, por meio da vivência da/na rotina escolar (BERGAMASCHI; ALMEIDA, 2013; ALBUQUERQUE; FRISON, 2014). Do mesmo modo, este resultado vai ao encontro do que Roth e colaboradores (1999) apontam sobre a dimensão tácita das possibilidades de ser professor/a, indicando que não é suficiente dizer ao/à licenciando/a o que e como fazer, mas é necessário experimentar e realizar, na prática, em conjunto com eles/as.

Por outro lado, este fenômeno marcado pela ausência de hierarquias na prática e pela atuação de licenciandos/as como professores/as opera discursivamente para práticas hegemônicas, buscando mitigar relações de poder e criar sentidos de pertença a comunidades específicas. Se, por um lado, pode-se supor que esta seja uma prática desejável, por outro, há que se reconhecer esta como uma estratégia para produção de hegemonias.

\section{O PIBID como entidade}

Alguns estudos críticos do discurso, que tratam dos modos como textos veiculam experiências de mundo dos falantes, exploram mecanismos léxico-gramaticais por meio dos quais "se constrói a experiência do mundo feito de processos, participantes e circunstâncias" (ALEXANDRE; RESENDE, 2010, p. 94). Com base nas categorias Sistema de Transitividade (HALLIDAY, 2004), e Representação de Atores Sociais (VAN LEEUWEN, 2008), é possível analisar quem são os responsáveis pelas ações, para quem elas se direcionam e em que circunstâncias isso se dá. Tendo como núcleo o processo que é realizado 


\section{Dossiê Especial: Experiências do PIBID na formação inicial e continuada de professores de línguas estrangeiras \\ HIBARINO \& NODARI (orgs) \\ Revista X, vol.1, 2015}

por um verbo, as diferentes configurações combinam diferentes tipos de entidades, i.e., participantes e, como tal constrói diferentes significados" (ALEXANDRE; RESENDE, 2010, p. 94).

Nos dados deste estudo, valemo-nos destas categorias para analisar os modos como o PIBID aparece representado nos textos das licenciandas, acreditando que estas construções de experiência indicam posicionamentos em relação ao Programa. Analisamos, com isto, os modos como os processos de identificação que acabamos de discutir são experienciados pelas licenciandas. $\mathrm{O}$ excerto seguinte ilustra a presente análise:

\section{Excerto 2: \\ Cristina: linhas 53-55}

Hoje eu nem mesmo falo que o PIBID foi um estágio, para mim, o PIBID significou muito mais, muito mesmo. Ele fez eu ter certeza que eu quero ser professora de Inglês [...] Muitas vezes eu penso que o PIBID me salvou porque demorei muito tempo para decidir o que eu "queria ser na vida", qual profissão seguir.

Patricia: linhas 16-17

O PIBID com certeza me ajudou a criar minha identidade como professora, e me ajudou a decidir se era realmente isso que eu queria.

\section{Priscila: linhas 27-28}

[...] posso dizer que o PIBID proporcionou esta experiência que me ajudou a me reconhecer como professora de inglês.

Estes recortes são exemplos de textos que retiram o PIBID da qualidade de prática social, iniciada e levada a cabo por pessoas, ou de circunstância em que práticas sociais se realizam, e o coloca na posição de agente de práticas. Isto é, o PIBID é representado como entidade que é e que significa algo, que faz algo, que salva, que ajuda a criar, ajuda a decidir e ajuda a reconhecer-se, e que proporciona alguma coisa. Figura, portanto, como uma entidade que realiza processos relacionais (ser, significar), processos materiais (fazer, salvar, ajudar) e que ajuda a realizar processos mentais (criar, decidir, reconhecer-se).

Ao assim representarem suas experiências de formação, as licenciandas posicionam o PIBID como aquele que realiza ações das quais são beneficiárias, personificando-o.

Cristina, ao afirmar que "eu nem mesmo falo que o PIBID foi um estágio", e que "o PIBID significou muito mais, muito mesmo", representa-o em distanciamento com uma prática social consolidada (o estágio) e em aproximação a algo marcado pelo intensificador muito, locucionado de duas formas diferentes (muito mais e muito mesmo). Na sequência, em "Ele fez eu ter a certeza ...", Cristina personifica o programa por meio do pronome pessoal ele 


\section{Dossiê Especial: Experiências do PIBID na formação inicial e continuada de professores de línguas estrangeiras \\ HIBARINO \& NODARI (orgs) \\ Revista X, vol.1, 2015}

e do verbo fazer - um processo material que expressa ações concretas realizadas por atores sociais e que, neste caso, tem como beneficiária a própria Cristina. É sobre ela que incide a certeza de "que eu quero ser professora de Inglês". Esta vontade está modalizada categoricamente e indica alto grau de comprometimento com o que ela diz (ter certeza em querer ser professora). Isto leva a supor o PIBID como ator responsável por sua decisão de ser professora e, portanto, como entidade que salva (“O PIBID me salvou”).

Na mesma direção parecem caminhar Patrícia e Priscila. Ambas interpretam o PIBID como aquilo que ajudou a reconhecer-se como professora ou criar identidade de professora. Em Patrícia também há um alto grau de comprometimento com esta experiência ("O PIBID com certeza me ajudou..."), o que permite supor quão fulcral foi o programa no seu desenvolvimento. Em Priscila, o programa é aquele que realiza a ação proporcionar ("O PIBID proporcionou esta experiência..."), quando quem pode proporcionar experiências são somente pessoas. Assim, o PIBID é (dis)posicionado como entidade salvadora, cultuada e enaltecida pelas três licenciandas, personificado e colocado como agente dos processos de identificação com a profissão.

\section{Uma entidade chamada PIBID}

Este texto surge da necessidade de se refletir sobre os modos como ordens do discurso se relacionam a práticas sociais e a transformações que afetam a educação e, de modo específico, a formação de professores/as em nível de ensino superior.

Nosso argumento, ao longo da discussão, dialoga com o conceito de tecnologização de discursos como "estratégias, técnicas e procedimentos por meio dos quais diferentes forças buscam tornar programas operacionais"16 (ROSE; MILLER, 1989, citados em FAIRCLOUGH, [1995] 2010, p. 137). Neste sentido, revisamos estudos que tratam do PIBID e analisamos narrativas de três licenciandas, bolsistas de iniciação à docência.

Quanto às pesquisas selecionadas, elas permitiram discutir os modos como práticas discursivas instanciadas nos espaços das universidades acomodam as tensões entre o discurso oficial da Capes e o discurso acadêmico, buscando um equilíbrio entre o papel do/a professor/a do ensino superior como pesquisador/a e como coordenador/a das práticas de

\footnotetext{
${ }^{16}$ strategies, techniques and procedures by means of which different forces seek to render programmes operable.
} 


\section{Dossiê Especial: Experiências do PIBID na formação inicial e continuada de professores de línguas estrangeiras \\ HIBARINO \& NODARI (orgs) \\ Revista X, vol.1, 2015}

formação docente. São estudos que, na tentativa de analisar e discutir os impactos do PIBID sobre o desenvolvimento de professores/as, constituem-se instrumentos poderosos na padronização e normatização de práticas discursivas que celebram o Programa de modo hegemônico. Isto porque a tecnologização de discursos passa pelo envolvimento de cientistas e de pesquisadores no processo de redesenhar e de oferecer treinamento com base na sua efetividade instrumental como, por exemplo, na eficácia do anúncio em vender ou, de interesse neste trabalho, na eficácia da parceria universidade-escola em formar professores/as. Esta é uma engenharia na qual as universidades não são somente espaços de consumo de políticas públicas, mas coprodutoras e anunciantes destas políticas que ajudam a naturalizar a manipulação das pessoas para propósitos institucionais (FAIRCLOUGH, 1994).

Como já dissemos, a criação de hegemonia por consenso é parte da estratégia dos processos de tecnologização de discursos. Hegemonia diz respeito ao aparente consenso sobre aspectos do mundo social que passam a ser vistos como naturais, transparentes e necessários (CHOULIARAKI; FAIRCLOUGH, 1999). Assim como boa parte dos resultados de pesquisa aos quais tivemos acesso para este trabalho, aqueles a que chegamos por meio da análise de textos produzidos por três licenciandas neste estudo refletem a naturalização daquilo que está na base do PIBID: o deslocamento da formação docente para o espaço da prática em sala de aula, a mitigação de relações de poder entre professores/as da educação superior, da educação básica e licenciandos/as e entre as instituições de ensino superior e de educação básica, bem como o disposicionamento de lugares sociais consolidados para professores/as que atuam em diferentes níveis de ensino. A organização discursiva consensualmente presente nos textos que discutimos e analisamos nos permite falar do PIBID como entidade, isto é, como algo com poder para agir. Seu caráter naturalizado e messiânico o torna resistente a leituras alternativas.

Isto traz implicações para as práticas de formação de professores/as que passam por transformações nas relações de poder e nas identidades profissionais. Sendo assim, mais estudos são necessários para que explanações críticas sejam consistentemente elaboradas. Dentre eles, julgamos pertinente que fossem consideradas as implicações (i) dos editais do governo federal, que inserem o PIBID em práticas discursivas neoliberais, sobre as relações entre as instituições acadêmicas e o público; (ii) do apagamento das relações de poder sobre as identidades institucionais e de professores/as; (iii) do deslocamento da formação de professores/as para o contexto da escola de educação básica como alternativa para 
Dossiê Especial: Experiências do PIBID na formação inicial e continuada de professores de línguas estrangeiras

HIBARINO \& NODARI (orgs)

Revista X, vol.1, 2015

reconstituição da natureza dialética de teoria-prática; (iv) do (dis)posicionamento de professores/as formadores/as para o lugar de coordenadores/as sobre os processos de produção de conhecimento.

Vale, portanto, ressaltar que processos de tecnologização de discursos são, como já dissemos, complexos e envolvem redes de práticas sociais, incluindo as discursivas, que conectam aspirações globais a atividades locais, levadas a cabo por indivíduos ou grupos. Tais processos constituem, de fato, uma engenharia dinâmica de reestruturação social e cultural que conta com vários mecanismos e estratégias que impactam nossos modos de (inter)agir, pensar e ser. $\mathrm{Na}$ medida em que, inseridos no universo destas práticas, transformamos nossas identidades e nos reposicionamos socialmente, ampliamos o potencial de ação mais ou menos resistente. O que nos parece essencial, no entanto, é que tenhamos maior clareza sobre estes aspectos para que nossas identidades não sofram de credibilidade e genuinidade.

\section{Agradecimento}

Agradecemos à CAPES pela concessão das bolsas PIBID que possibilitaram a realização desta pesquisa.

\section{Referências}

ALBUQUERQUE, M. P.; FRISON, L. M. B.; PORTO, G. C. Memorial de formação escrito no decorrer da prática docente: aprendizagens sobre alfabetização e letramento. Revista Brasileira de Estudos Pedagógicos, v. 95, n. 239, 2014, Pp. 73-86.

ALEXANDRE, M. F.; RESENDE, V. de M. Representação discursiva da pobreza extrema análise discursiva crítica de um testemunho publicado em editorial da revista Cais. Revista Latinoamericana de Estudios del Discurso, v. 10, n. 2, 2010, Pp. 87-105.

ANDRÉ, M. Políticas e programas de apoio aos professores iniciantes no Brasil. Cadernos de Pesquisa, v. 42, n. 145, 2012, Pp. 112-129.

BERGAMASCHI, M. A.; ALMEIDA, D. B. Memoriais escolares e processos de iniciação à docência. Educação em Revista, v. 29, n. 2, 2013, Pp. 15-41.

CHOULIARAKI, L.; FAIRCLOUGH, N. Discourse in late modernity: rethinking critical discourse analysis. Edinburgh: Edinburgh University Press, 1999.

FAIRCLOUGH, N. Critical discourse analysis and the marketization of public discourse: the universities. Discourse \& Society, v. 4, n. 2, 1993, Pp. 133-168.

Conversationalization of public discourse and the authority of the consumer. IN: KEAT, R.; WHITELEY, N.; ABERCROMBIE, N. (Ed.). The authority of the consumer. London: Routledge, 1994, Pp. 235-248. 
Dossiê Especial: Experiências do PIBID na formação inicial e continuada de professores de línguas estrangeiras

HIBARINO \& NODARI (orgs)

Revista X, vol.1, 2015

Critical Discourse Analysis: the critical study of language. 2 ed. Harlow: Pearson Education Limited, [1995] 2010.

FETZNER, A. R.; SOUZA, M. E. V. Concepções de conhecimento escolar: potencialidades do Programa Institucional de Bolsa de Iniciação à Docência. Educação e Pesquisa, v. 38, n. 3, 2012, Pp. 683-694.

HALLIDAY, M. An introduction to Functional Grammar. Revisão Christian Matthiessen. London: Hodder Arnold, 2004.

HARGREAVES; A.; FULlAN, M. Professional Capital: transforming teaching in every school. Columbia University: Teachers College Press, 2012.

KENNEDY, A.; DOHERTY, R. Professionalism and partnership: panaceas for teacher education in Scotland? Journal of Education Policy, v. 27, n. 6, 2012, Pp. 835-848.

MATEUS, E. Práticas de formação colaborativa de professores/as de inglês: representações de uma experiência no PIBID. Revista Brasileira de Linguística Aplicada, v. 13, n. 4, 2013, Pp. 1107-1130.

Um esboço crítico sobre "parceria" na formação de professores/as. Educação em Revista, 2014, no prelo.

MATEUS, E.; RESENDE, V. M. (Dis)posicionamentos em práticas sociais recontextualizadas: uma análise discursiva crítica do PIBID. IN: VIEIRA, V. C.; RESENDE, V de M. (orgs.). Práticas Socioculturais e Discurso: debates transdisciplinares em novas reflexões. Covilhã, UBI, LabCom, Livros LabCom, 2014, Pp. 75-94.

NEITZEL, A. A.; PAREJA, C. J. M.; HOCHMANN, S. Práticas de leitura no ensino médio: o PIBID de Letras. Revista Brasileira de Estudos Pedagógicos, v. 94, n. 238, 2013, Pp. 770794.

PICONI, L; MATEUS, E. Ressignificações de identidades de professores: uma análise do encontro com o outro. IN: REIS, S.; VAN VEEN, K.; GIMENEZ, T. (Org.). Identidades de Professores de Línguas. Londrina: Eduel, 2011, Pp. 271-293.

ROTH, M-W.; MASCIOTRA, D.; BOYD, N. Becoming-in-the-classroom: a case study of teacher development through coteaching. Teaching and Teacher Education, v. 15, 1999, Pp. 771-784.

SANTOS, A. S.; SENA, J. S.; BARBOSA, A. M. A. Uma nova palavra: Pibideiro(a). In: Fórum Nacional de Critica Cultural, 2., 18 a 21 de novembro de 2010, Anais... Educação Básica e cultura: diagnóstico, proposições e novos agenciamentos. Disponível em: http://www.poscritica.uneb.br/anais-eletronicos/arquivos/26\%20-

\%20UMA\%20NOVA\%20PALAVRA\%20PIBIDEIRO\%20(A).pdf Acesso em: 12 out. 2012.

SAVIANI, D. O Plano de Desenvolvimento da Educação: análise do projeto do MEC. Educação e Sociedade, Campinas, v. 28, n. 100 - Especial, out. 2007, Pp. 1231-1255. Disponível em: 〈http://www.cedes.unicamp.br>. Acesso em: 10 mar. 2011.

SCHEIBE, L. Valorização e formação dos professores para educação básica: questões desafiadoras para um novo Plano Nacional de Educação. Educação \& Sociedade, Campinas, v. 31, n. 112, jul.-set. 2010, Pp. 981-1000. Disponível em: 〈http://www.cedes.unicamp.br〉. Acesso em: 10 jun. 2011. 
Dossiê Especial: Experiências do PIBID na formação inicial e continuada de professores de línguas estrangeiras

HIBARINO \& NODARI (orgs)

Revista X, vol.1, 2015

SCHÖN, D. A. Coaching reflective teaching. IN: GRIMMETT, P. P.; ERICKSON, G. L. (Ed.). Reflection in Teacher Education. New York: Teachers College Press, 1988. Pp. 1929.

SMYTH, J. Teachers' work and the politics of reflection. American Educational Research Journal, v. 29, n. 2, Summer 1992, Pp. 267-300.

VAN LEEUWEN, T. Discourse and practice: new tools for critical discourse analysis. Oxford: Oxford University Press, 2008.

ZEICHNER, K. M. Educating reflective teachers for learner centered-education: possibilities and contradictions. IN: GIMENEZ, T. (Org.). Ensinando e aprendendo inglês na universidade: formação de professores em tempos de mudança. Londrina: ABRAPUI, 2003, Pp. 3-19. 